\title{
Sudden Deafness Caused by Lifestyle Stress: Pathophysiological Mecha- nisms and New Therapeutic Perspectives
}

\author{
Miguel A. Lopez-Gonzalez ${ }^{* a}$, Carmen Lopez-Lorente $^{\mathrm{b}}$, Antonio Abrante ${ }^{\mathrm{a}}$, Pedro Benaixa ${ }^{\mathrm{a}}$ and \\ Francisco Esteban ${ }^{\mathrm{a}}$ \\ ${ }^{a}$ Department of Otorhinolaryngology, Virgen del Rocio University Hospital, Avda Manuel Siurot s/n, 41013-Sevilla, \\ Spain \\ ${ }^{b}$ Medicine Faculty, University of Sevilla, Avda Sanchez Pizjuan s/n, 41009-Sevilla, Spain
}

\begin{abstract}
Stress caused by lifestyles in industrialised countries can affect numerous illnesses. Side effects of stress at the level of microcirculation are vasoconstriction, haemoconcentration and vascular occlusion. Reduced or restricted blood flow in the internal auditory artery of the inner ear can lead to sudden deafness. The extent of the damage depends on whether vascular occlusion is momentary or prolonged. The hypothesis put forward is that stressful situations in everyday life can cause differing degrees of sudden deafness. Treatment is based on three main actions, including elimination of the acute stress, re-establishment of blood flow to the inner ear and management of overall patient stress for a complete recovery. Furthermore, another therapeutic option exists, and this alternative is based on the hypothesis that hair cells in the cochlea can be physical rehabilitated with sounds. The acoustic stimulus places pressure on the tympanic membrane, which increases pressure via the ossicles (malleus, incus and stapes). The stapes in the oval window move the perilymph, producing waves that move the endolymph. The tectorial membrane moves the cilia of the external and internal hair cells. Massaging the cilia causes hair cells in the cochlea to contract each other, thus emitting an electric impulse. This impulse through the cochlear nerves and the auditory system produces sound perception in the auditory cortex. The sound is applied in the ear with sudden deafness, even though cophosis, a complete loss of hearing, has occurred. In conclusion, sudden deafness may be caused by stress, being the treatment the elimination of stress; re-establish the blood flow to the inner ear and a physical rehabilitation with sounds of cochlear hair cells to reverse sudden deafness.
\end{abstract}

\section{BACKGROUND}

Sudden deafness is a loss of hearing that develops over several hours [1], and it may be accompanied by tinnitus and vertigo. It affects between 5 and 20 out of every 100,000 individuals [2]. Many aetiologies have been proposed for sudden deafness, including cochlear membrane rupture, microangiopathic processes, viral infection, autoimmune disorders, Ménière's disease, schwannoma and meningioma. Processes related to stress have also been investigated in association with sudden deafness. Specifically, studies have examined stressful lifestyles; emotional, psychosocial or occupational disorders and personalities that are prone to stress [3-7]. Taking into account all of the above aetiopathogeneses, no pathophysiological mechanisms have been established to explain sudden deafness. There has recently been an increase in information potentially explaining the pathophysiological problems caused by stress, which could elucidate how sudden deafness progresses.

\section{HYPOTHESIS: STRESS PRODUCES SUDDEN DEAF- NESS. PATHOPHYSIOLOGICAL MECHANISMS}

Animal studies. Experiments carried out on stressed rats have shown an increased aggregation of red blood cells,

\footnotetext{
*Address correspondence to this author at the Department of Otorhinolaryngology, Virgen del Rocio University Hospital, Avda Manuel Siurot s/n, 41013-Sevilla, Spain; Tel: +34955016938; Fax: +34955016905;

E-mail:malopez@cica.es
}

which leads to haemoconcentration, with reduced blood flow in the microcirculation [8]. The occlusion of blood flow in the inner ear has a greater impact on more vulnerable structures such as the cochlea. The cochlea is more affected by these types of changes than the vestibular labyrinth, for example. The critical areas in the cochlea include the external and internal hair cells, along with the stria vascularis [9].

Human studies. Potential pathophysiological mechanisms for the changes in the ear include vasoconstriction, with liquids escaping from the bloodstream because of the activity of the sympathetic nervous system. Additionally, hyperviscosity of the plasma and the blood; higher concentrations of proteins, fibrinogen, free fatty acids and interleukin- 1 in the plasma; increased platelets and leukocytes; augmented platelet adhesiveness and aggregation; and higher blood pressure are also potential results of stress. The plasma volume is reduced, as is blood flow and filterability [10-20]. Stress produces vasoconstriction, haemoconcentration and reduced blood movement throughout the body. For the purpose of this pathology, stress refers to any type of physical, mental, psychological and psychoemotional stress. Stress may be acute and chronic. There are psychosomatic influences on the lifestyle of each person and therefore the way in which he/she becomes ill. Emotional reactions associated with a stressful situation result in abnormalities in blood rheology, causing blood circulation to deteriorate due to a reduced flow from increased haemoconcentration [21]. 
At the microcirculation level within the heart this same process triggers angina and heart attacks [22]. Within the inner ear, this process can trigger sudden deafness (Fig. 1).

The hypothesis supported by this knowledge explains how stress can trigger sudden deafness.

\section{THERAPEUTIC PERSPECTIVES}

Therapeutic measures must be established in the following points:

1. Acute stress elimination: Medical-therapeutic advice may be used, along with relaxation techniques and sedative medication (hydroxyzine, halazepam, alprazolam).

2. Re-establishment of blood flow to the inner ear: In addition to removing the acute stress, haemodilution [23], blocking the cervical sympathetic chain [10], corticosteroids [24] and vasodilators [25] can be utilized to help return normal blood flow to the inner ear.

3. Stress management: The patient must be able to manage stressful situations. The elimination of prolonged stress is essential for recovery from sudden deafness. If the patient continues to experience stress during the post-acute phase, the prognosis gets worse since the factors causing the episode are maintained. The individual's personality is therefore extremely important. Cognitive-behavioural therapy is advised.

4. Inner ear hair cells physical rehabilitation. This new approach is based in animal studies. Sound stimulus leads to improvements or recovery in hearing. Chinchillas were subjected to acoustic deprivation following an acoustic trauma, which consisted of an ossiculectomy on one of their ears. The elimination of the ossicles results in receiving less ambient sound to that ear. In the remaining non-surgical ear, the acoustic trauma resulted in damage to the hair cells and hypoacusia. However, increased damage occurred to the hair cells in the operated ear, as well as greater hypoacusia [26]. In a second study on guinea pigs suffering from bilateral acoustic trauma, the group of animals that received sound conditioning seemed to recover normal hearing, while the group that did not receive sound conditioning developed hypoacusia [27]. In a third study on mice with a genetic predisposition for sensorineural deafness as adults, one group was subjected to a moderately intense sound while the other group had no sound treatment. The group who received sound stimulation presented less presbycusis and less damage to the external and internal hair cells, the spiral ganglion and the ventral cochlear nucleus [28]. Finally, a fourth study on cats demonstrated that animals exposed to acoustic trauma and sound stimulation did not undergo reorganization of the tonotopic map. Therefore, they did not suffer from deafness, tinnitus or hyperacusis. In contrast, in the group of cats that was not subjected to sound stimulation, acoustic trauma caused reorganization of the tonotopic map, along with deafness, tinnitus and hyperacusis [29].

\section{HYPOTHESIS: PHYSICAL REHABILITATION OF INNER EAR HAIR CELLS AIDS RECOVERY}

Physical rehabilitation consists of moving the cilia of the external and internal hair cells. These may be reached through the liquids contained in the inner ear. The endolymph bathes both types of cells. The endolymph may be moved by placing pressure on the tympanic membrane. This pressure may be applied by sounds introduced through the ear canal (Fig. 2). The type of sound applied may be white noise, which would stimulate all auditory frequencies at an intensity sufficient to produce wave movements in the endolymph. These changes in the endolymph will in turn lead to movement to the tectorial membrane, causing action in the cilia of the cochlear hair cells. If the intensity of the sound is too high, it may cause acoustic trauma, and if it is too low, the resulting movement of the cilia may be insufficient. Average values of 60dB SPL seem to be adequate. White noise will evenly stimulate all frequencies at this intensity.

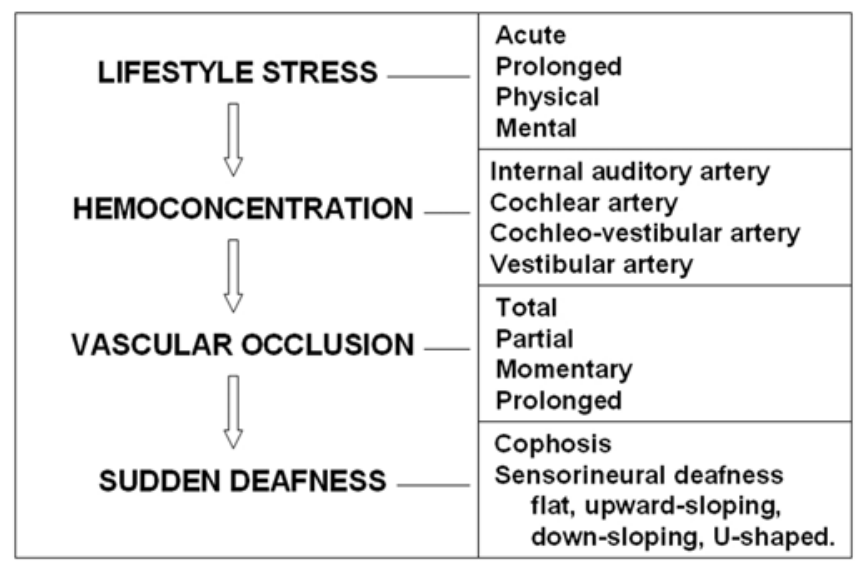

Fig. (1). Hypothesis: lifestyle stress produces sudden deafness. The pathophysiological mechanisms, induced by stress, triggering sudden deafness include vasoconstriction, haemoconcentration and vascular occlusion. The degree of sudden deafness depends on predetermined factors of blood flow, which are shown in the right part of the figure.

\begin{tabular}{|c|l|}
\hline SOUND & $\begin{array}{l}\text { Sound } \\
\text { Tympanum } \\
\text { Ossicles } \\
\text { Oval window } \\
\text { Waves of perilymph } \\
\text { Waves of endolymph } \\
\text { Tectorial membrane } \\
\text { Ciliar movement } \\
\text { Contraction of hair cells } \\
\text { Of INNER EAR HAIR CELLS }\end{array}$ \\
Electric impulse \\
Cochlear nerve \\
Auditory pathways \\
Auditory cortex \\
Sound perception
\end{tabular}

Fig. (2). Hypothesis: physical rehabilitation of inner ear hair cells. The cilia of the hair cells are massaged using sounds. Movement of the cilia produces cellular contraction and nerve impulses. Physical movement of the cell helps recover its hearing function. The entire sequence is shown in the right side of the figure, starting with the sound and ending with the sound perception.

This mode of treatment may be adequate for patients who suffer from incomplete sudden deafness or in cases of sudden cophosis. Patients with sudden cophosis will not initially 
hear the sound applied. They will begin to hear it as they recover their hearing.

Sound stimulation can be personalised according to the audiometric configuration, which consists of cophosis (complete loss of hearing) and a flat curve, an upward-sloping curve, a downward-sloping curve or a U-shaped audiometric curve. In cases of cophosis and a flat audiometric curve, uniform sound stimulation at all frequencies may be adequate. In upward-sloping configurations, low and medium frequencies are principally stimulated. In downward-sloping configurations, high and medium frequencies are more intensely stimulated. Finally, medium frequencies are stimulated for U-shaped configurations (Fig. 3). Alternative sounds that may be used, instead of white noise, include more complex musical sounds or sounds of nature. The practical application of this hypothesis is simple. Sounds should be added to the routine treatment of sudden deafness.

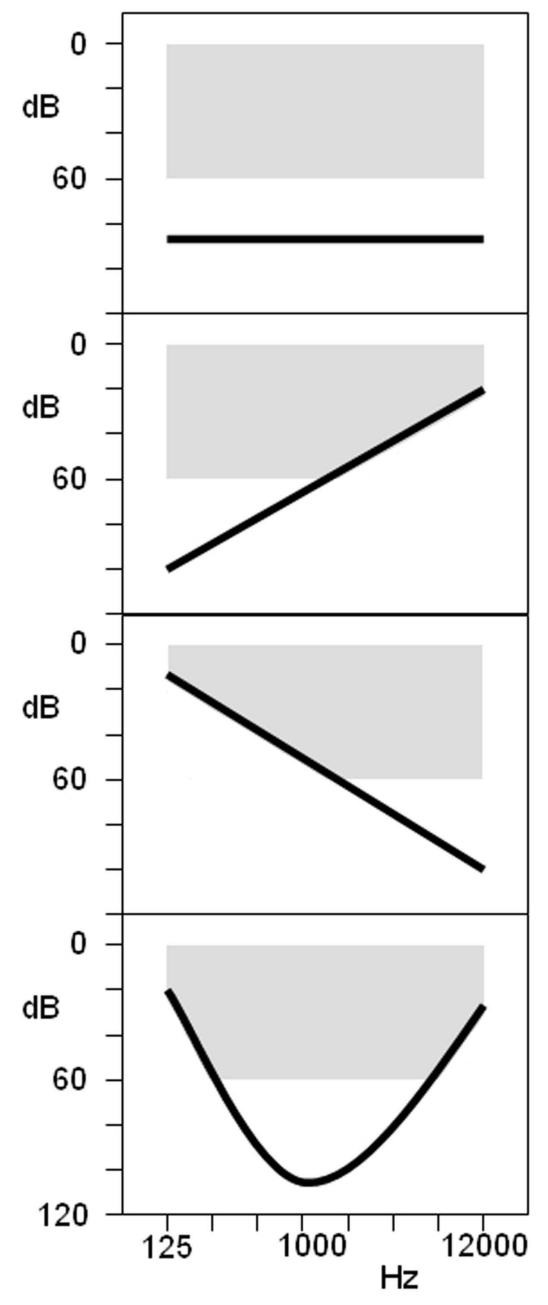

Fig. (3). Personalising sound stimulation. Sounds are applied in accordance with the audiometric configuration. From top to bottom, flat audiometric configuration and cophosis receive the same type of sound. An upward-sloping configuration receives a less intense sound in the better hearing acute frequency zone. A downwardsloping configuration receives a less intense sound in the better hearing bass frequency zone. A U-shaped configuration receives a less intense sound in the better hearing high and low frequency zones. The shaded zones correspond to the sound applied.

\section{CONCLUSIONS}

Sudden deafness can be triggered by stress, which leads to vasoconstriction, haemoconcentration and microcirculation occlusion in the inner ear. Treatment consists of eliminating the stress, as well as managing future stress to achieve a full recovery, re-establishing blood flow and physically rehabilitating the cochlear hair cells using sounds.

\section{ACKNOWLEDGEMENTS}

Grant 0406 of the TRI-Tinnitus Research Initiative partially supported this work.

\section{REFERENCES}

[1] Mattox DE, Simmons FB. Natural history of sudden sensorineural hearing loss. Ann Otol Rhinol Laryngol 1977; 86: 463-80.

[2] Olzowy B, Osterkorn D, Suckfull M. The incidence of sudden hearing loss is greater than previously assumed. MMW Fortschr Med 2055; 147: 37-8.

[3] Greuel H. Personality markers as a risk for sudden deafness. HNO 1986; 34: 146-8.

[4] Neuser J, Knoop T. Sudden idiopathic hearing loss: psychopathology and antecedent stressful life-events. $\mathrm{Br} \mathrm{J}$ Med Psychol 1986; 59: 245-51.

[5] Bernal-Sprekelsen M, Hormann K, Lamparter U. Sudden deafness and stress: a retrospective analysis. Acta Otorrinolaringol Esp 1990; 41: 93-5.

[6] Kroger F, Lamprecht J, Walte D, Muller A. Coping with stress and self-awareness in idiopathic sudden deafness. Psychother Psychosom Med Psychol 1996; 46: 298-303.

[7] Schmitt C, Patak M, Kroner-Herwig B. Stress and the onset of sudden hearing loss and tinnitus. Int Tinnitus J 2000; 6: 41-9.

[8] Katiukhin LN. The role of the rheological parameters of erythrocytes in maintenance of the blood flow structure in stressed rats. Aviakosm Ekolog Med 2002; 36: 64-7.

[9] Kimura RS. Animals models of inner ear vascular disturbances. Am J Otolaryngol 1986; 7: 130-9.

[10] Singleton GT. Cervical sympathetic chain block in sudden deafness. Laryngoscope 1971; 81: 734-6.

[11] Maass B. The significance of platelet adhesiveness and aggregation and free fatty acids by functional disorders of the internal ear. Arch Otorhinolaryngol 1975; 209: 263-70.

[12] Strauss P, Kunkel A. Sympathetic Trunk treatment or infusion therapy in cases of sudden deafness. Laryngol Rhinol Otol (Stuttg.) 1977; 56: 366-71.

[13] Stuart J. The acute-phase reaction and haematological stress syndrome in vascular disease. Int J Microcir Clin Exp 1984; 3: 115-29.

[14] Ernst E, Weihmayr T, Schmid M, Baumann M, Matral A. Cardiovascular risk factors and hemorheology. Physical fitness, stress and obesity. Atherosclerosis 1986; 59: 263-9.

[15] Ohinata Y, Makimoto K, Kawakami M, Haginomori S, Araki M, Takahashi H. Blood flow in common and vertebral arteries in patients with sudden deafness. Ann Otol Rhinol Laryngol 1997; 106: 27-32.

[16] Boudova L, Cisarik F, Barackova M, Brandejsky P. The effect of physical stress on rheological properties of blood. Sb Lek 1995; 96: 111-20.

[17] Patterson SM, Marsland AL, Manuck SB, Kameneva M, Muldoon MF. Acute hemoconcentration during psycological stress: assessment of hemorheologic factors. Int J Behav Med 1998; 5: 204-12.

[18] Steptoe A, Kunz-Ebrecht S, Rumley A, Lowe GD. Prolonged elevations in haemostatic and rheological responses following psychological stress in low socioeconomic status and women. Thromb Haemost 2003; 89: 83-90.

[19] Bacon SL, Ring C, Lip GY, Carroll D. Increases in lipids and immune cells in response to exercise and mental stress in patients with suspected coronary artery disease: effects of adjustment for shifts in plasma volume. Biol Psychol 2004; 65: 237-50.

[20] Veldhuijzen van Zanten JJ, Thrall G, Wasche D, Carroll D, Ring C. The influence of hydratation on stress-induced hemoconcentration. Psychophysiology 2005; 42: 98-107.

[21] Takeichi M, Sato T. Studies on the psychosomatic functioning of ill-health according to eastern and western medicine. Two treat- 
ment methods using kampo medication for stress-related and lifestyle disease. Am J Chin Med 1999; 27: 315-29.

[22] Lee BK, Durairaj A, Mehra A, Wenby RB, Meiselman HJ, Alexy T. Hemorheological abnormalities in stable angina and acute coronary syndromes. Clin Hemorheol Microcirc 2008; 39: 43-51.

[23] Kellerhals B. Treatment of acute inner ear deafness (sudden deafness and acoustic trauma). Laryngol Rhinol Otol (Stuttg.) 1977; 56: $357-63$.

[24] Wei BB, Mubiru S, O'Leary S. Steroids for idiopathic sudden sensorineural hearing loss. Cochrane Database Syst Rev 2006; (1): CD003998.

[25] Gersdorff M, Franceschi D. Value of piracetam in the treatment of sudden idiopathic deafness. Preliminary report. Ann Otolaryngol Chir Cervicofac 1986; 103: 283-5.
[26]

Fukushima M, White P, Harrison RV. Influence of acoustic deprivation on recovery of hair cells after acoustic trauma. Hear Res 1990; 50: 107-18.

[27] Niu X, Tahera Y, Canlon B. Protection against acoustic trauma by forward and backward sound conditioning. Audiol Neurootol 2004 9: 265-73.

[28] Willott JF, Bross LS. Effects of prolonged exposure to an augmented acoustic environment on the auditory system of middleaged C57BL/6J mice: cochlear and central histology and sex differences. J Comp Neurol 2004; 472: 358-70.

[29] Noreña AJ, Eggermont JJ. Enriched acoustic environment after noise trauma reduces hearing loss and prevents cortical map reorganization. J Neurosci 2005; 25: 699-705.

(C) Lopez-Gonzalez et al.; Licensee Bentham Open

This is an open access article licensed under the terms of the Creative Commons Attribution Non-Commercial License (http://creativecommons.org/licenses/by$\mathrm{nc} / 3.0 /$ ) which permits unrestricted, non-commercial use, distribution and reproduction in any medium, provided the work is properly cited. 